\title{
A Spontaneous Mutation Involving Kcnq2 (Kv7.2) Reduces M-Current Density and Spike Frequency Adaptation in Mouse CA1 Neurons
}

\author{
James F. Otto, ${ }^{1}$ Yan Yang, ${ }^{2}$ Wayne N. Frankel, ${ }^{2}$ H. Steve White, ${ }^{1}$ and Karen S. Wilcox ${ }^{1}$ \\ ${ }^{1}$ Anticonvulsant Drug Development Program, Department of Pharmacology and Toxicology, University of Utah, Salt Lake City, Utah 84112, and \\ ${ }^{2}$ The Jackson Laboratory, Bar Harbor, Maine 04609
}

\begin{abstract}
The M-type $\mathrm{K}^{+}$current $\left[I_{\mathrm{K}(\mathrm{M})}\right]$ activates in response to membrane depolarization and regulates neuronal excitability. Mutations in two subunits (KCNQ2 and KCNQ3; Kv7.2 and Kv7.3) that underlie the M-channel cause the human seizure disorder benign familial neonatal convulsions (BFNC), presumably by reducing $I_{\mathrm{K}(\mathrm{M})}$ function. In mice, the Szt1 mutation, which deletes the genomic DNA encoding the KCNQ2 $\mathrm{C}$ terminus and all of CHRNA4 (nicotinic acetylcholine receptor $\alpha 4$ subunit) and ARFGAP-1 (GTPase-activating protein that inactivates ADP-ribosylation factor 1), reduces seizure threshold, and alters M-channel pharmacosensitivity. Genomic deletions affecting the $\mathrm{C}$ terminus of KCNQ2 have been identified in human families with BFNC, and truncation of the C terminus prevents proper KCNQ2/KCNQ3 channel assembly in Xenopus oocytes. We showed previously that Szt1 mice have a reduced baseline seizure threshold and altered sensitivity to drugs that act at the M-channel. Specifically, the proconvulsant M-channel blocker linopirdine and anticonvulsant enhancer retigabine display increased and decreased potency, respectively, in Szt1 mice. To investigate the effects of the Szt1 mutation on $I_{\mathrm{K}(\mathrm{M})}$ function explicitly, perforated-patch electrophysiology was performed in CA1 pyramidal neurons of the hippocampus in brain slices prepared from C57BL/6J-Szt1/+ and control C57BL/6J $+/+$ mice. Our results show that $S z t 1$ reduces both $I_{\mathrm{K}(\mathrm{M})}$ amplitude and current density, inhibits spike frequency adaptation, and alters many aspects of M-channel pharmacology. This is the first evidence that a naturally occurring $K c n q 2$ mutation diminishes the amplitude and function of the native neuronal $I_{\mathrm{K}(\mathrm{M})}$, resulting in significantly increased neuronal excitability. Finally, the changes in single-cell biophysical properties likely underlie the altered seizure threshold and pharmacosensitivity reported previously in Szt1 mice.
\end{abstract}

Key words: M-current; KCNQ2; C-terminal deletion; spike frequency adaptation; BFNC; retigabine

\section{Introduction}

The M-current $\left[I_{\mathrm{K}(\mathrm{M})}\right]$ is a slowly activating voltage-gated $\mathrm{K}^{+}$ channel that is tonically active at resting membrane potential and activates more strongly at depolarizing potentials (Brown and Adams, 1980; Constanti and Brown, 1981). $I_{\mathrm{K}(\mathrm{M})}$ activation repolarizes the cell and regulates neuronal excitability by controlling the generation and frequency of action potentials (Marrion, 1997). Accordingly, direct M-channel blockers and enhancers facilitate and inhibit action potential generation, respectively (Aiken et al., 1995; Otto et al., 2002). In relation to epilepsy, the M-channel blocker linopirdine is proconvulsant, whereas the enhancer retigabine is anticonvulsant (Flagmeyer et al., 1995; Ros-

Received Dec. 10, 2004; revised Dec. 13, 2005; accepted Jan. 5, 2006.

This work was supported by National Institutes of Health Grants NS544210 (K.S.W.), NS40246 (W.N.F., H.S.W.), and NS31348 (W.N.F.), a grant from the Primary Children's Medical Center Foundation (K.S.W.), and a Jackson Laboratory postdoctoral fellowship (Y.Y.). We thank Dr. Edward Cooper for critical reading and helpful comments, Dr. Barbara Beyer for genotyping and Carolyne Dunbar for maintaining the mouse breeding colony at The Jackson Laboratory, Sue 0. Hall for editing, and Dr. Peter West for technical assistance with the figures.

Correspondence should be addressed to Dr. Karen S. Wilcox, Anticonvulsant Drug Development Program, Department of Pharmacology and Toxicology, University of Utah, 20 South 2030 East, Room 408, Salt Lake City, UT 84112. E-mail: karen.wilcox@hsc.utah.edu.

DOI:10.1523/JNEUROSCI.1575-05.2006

Copyright $\odot 2006$ Society for Neuroscience $\quad$ 0270-6474/06/262053-07\$15.00/0 tock et al., 1996; Dost and Rundfeldt, 2000; Otto et al., 2004), and KCNQ2 and KCNQ3 gene mutations cause benign familial neonatal convulsions (BFNC), an idiopathic generalized human epilepsy (Biervert et al., 1998; Singh et al., 1998). Consistent with the role of $I_{\mathrm{K}(\mathrm{M})}$ and the fact that mutations in KCNQ2 and KCNQ3 subunits cause epilepsy, mutant KCNQ2/KCNQ3 channels expressed in Xenopus oocytes display decreased current amplitude (Schroeder et al., 1998). Studies were conducted recently in mice conditionally overexpressing the Kcnq2 G279S mutation (Peters et al., 2005). $I_{\mathrm{K}(\mathrm{M})}$ amplitude was reduced and neuronal excitability was increased in these mice; however, the acute mutant Kcnq2 overexpression was found to significantly alter the expression of wild-type KCNQ2 and KCNQ3. Thus, the effects of a naturally occurring $K c n q$ mutation on the native neuronal $I_{\mathrm{K}(\mathrm{M})}$ have still not been characterized.

To this end, Yang et al. (2003) identified a spontaneous deletion mutation in mice, $S z t 1$, that deletes the genomic region encoding most of the KCNQ2 subunit $\mathrm{C}$ terminus, as well as the Chrna4 (nicotinic acetylcholine receptor $\alpha 4$ subunit) and Arfgap1 (GTPase-activating protein that inactivates ADPribosylation factor 1) genes (Yang et al., 2003). In a phenotype similar to that of a previous Kcnq2 knock-out model (Watanabe et al., 2000), Szt1/Szt1 mice die of lung atelectasis shortly after 
birth. Szt1/+ mice are viable and display decreased seizure threshold and altered sensitivity to drugs that modify the M-channel (Otto et al., 2004), but the specific contribution of the Kcnq2 component of this deletion has not been characterized. Because the hippocampus is heavily implicated in epilepsy and because Kcnq2, Kcnq3, and Kcnq5 mRNA are highly expressed in the CA1 pyramidal cell layer (Shah et al., 2002), we sought to characterize $I_{\mathrm{K}(\mathrm{M})}$ function in CA1 hippocampal neurons of Szt1/+ (Szt1) and wild-type mice using the perforated-patch electrophysiology technique in the acute brain slice preparation.

The experiments presented here were designed to test the hypothesis that Szt1 alters baseline $I_{\mathrm{K}(\mathrm{M})}$ function and pharmacology. We conclude that CA1 neurons in Szt1 mice exhibit decreased $I_{\mathrm{K}(\mathrm{M})}$ amplitude and current density compared with that of wild-type C57BL/6J-B6+/+ (B6) littermates. Moreover, action potential accommodation is compromised in Szt1 CA1 neurons. These results are the first to show that a naturally occurring Kcnq2 mutation attenuates native $I_{\mathrm{K}(\mathrm{M})}$ amplitude and consequently increases neuronal excitability. We also detail several differences in $I_{\mathrm{K}(\mathrm{M})}$ pharmacology in Szt1 CA1 neurons, including increased sensitivity to linopirdine (LPD) and decreased sensitivity to retigabine (RGB). In addition, Szt1 CA1 neurons are essentially insensitive to tetraethylammonium (TEA), a blocker of KCNQ2 subunit-containing M-channels. These results shed significant light on the consequences of M-channel mutation as it relates to neuroexcitability and seizure generation and thus accentuate $I_{\mathrm{K}(\mathrm{M})}$ as a therapeutic target for the treatment of epilepsy.

\section{Materials and Methods}

Szt1 and B6 mice. Eight- to 12-week-old coisogenic male C57BL/6JSzt1/+ (Szt1) mice (15-25 g) and their B6 littermates, obtained from a research colony at the The Jackson Laboratory (Bar Harbor, ME), were used for all electrophysiology experiments. Animals were allowed access to food and water ad libitum and were housed in a temperature- and light-controlled ( $12 \mathrm{~h} \mathrm{light/dark} \mathrm{cycle)} \mathrm{environment.} \mathrm{All} \mathrm{animal} \mathrm{care} \mathrm{and}$ experimental manipulations were approved by the Institutional Animal Care and Use Committee of the University of Utah and are in accordance with the National Institutes of Health Guide for the Care and Use of Laboratory Animals.

Drugs. For electrophysiology experiments, stock solutions of RGB (0.01-0.10 M) were made in 50\% DMSO on the day of the experiment and added to the brain slice perfusion Ringer's solution (see below). The working concentration of DMSO was kept below $0.01 \%$. Stocks of LPD $(0.01-0.10 \mathrm{M})$ were made in $10 \% \mathrm{HCl}$ and frozen. Aliquots of LPD were thawed and added to perfusion Ringer's solution on the day of each experiment. TEA was added directly to perfusion Ringer's solution. For drug applications, slices were perfused with drug-containing Ringer's solution for a total of 30-60 min, until full effect was achieved and remained constant for at least $10 \mathrm{~min}$. All chemicals were purchased from Sigma (St. Louis, MO), except RGB, which was generously supplied by VIATRIS (Frankfurt, Germany).

Acute brain slice preparation. Brain slices were prepared from B6 and Szt1 mice in a manner similar to previously described methods (Barton et al., 2004). Briefly, mice were anesthetized with sodium pentobarbital (25 $\mathrm{mg} / \mathrm{kg}$ ) and decapitated, and their brains were quickly removed and placed in oxygenated Ringer's solution containing the following (in $\mathrm{mm}$ ): 200 sucrose, $26 \mathrm{NaHCO}_{3}, 10$ glucose, $3 \mathrm{KCl}, 2 \mathrm{MgSO}_{4}, 2 \mathrm{CaCl}_{2}$, and 1.4 $\mathrm{NaH}_{2} \mathrm{PO}_{4}$. Brains were trimmed and mounted on a chuck, and 350- $\mu \mathrm{m}-$ thick coronal slices were cut using a Vibratome slicer (Vibratome, St. Louis, MO). Slices were then transferred to a holding chamber and allowed to incubate for $>1 \mathrm{~h}$ in oxygenated Ringer's solution similar to the above solution, but with $126 \mathrm{~mm} \mathrm{NaCl}$ in place of sucrose. The $\mathrm{NaCl}$ Ringer's solution $\mathrm{pH}$ was maintained at 7.37-7.40 with $\mathrm{NaOH}$ and continuous bubbling with $95 \% \mathrm{O}_{2} / 5 \% \mathrm{CO}_{2}$, at 305-310 mOsm.

Electrophysiological measurements. Whole-cell perforated-patch re- cordings were obtained from CA1 pyramidal neurons in the acute brain slice preparation using a MultiClamp 700A amplifier (Molecular Devices, Menlo Park, CA). Signals in voltage-clamp and current-clamp modes were acquired at 10 and $20 \mathrm{kHz}$ and filtered at 2 and $10 \mathrm{kHz}$, respectively, for off-line analysis using Clampfit 8 (Molecular Devices). Glass capillaries (World Precision Instruments, Sarasota, FL) were pulled to 2.0-3.2 M $\Omega$ resistances using a micropipette electrode puller (Sutter Instruments, Novato, CA). Input and series resistance values of $80-120$ and $<15 \mathrm{M} \Omega$, respectively, were used as selection criteria for accepting recordings. Capacitance compensation and bridge balance functions were used for voltage-clamp and current-clamp experiments, respectively. Amphoterecin B $(0.45-0.5 \mathrm{mg} / \mathrm{ml})$ was dissolved in the intracellular solution containing the following (in $\mathrm{mm}$ ): 140 potassium gluconate, $10 \mathrm{HEPES}, 10 \mathrm{KCl}$, and $0.2 \mathrm{MgCl}_{2}$, $\mathrm{pH}$ adjusted to 7.28 with $\mathrm{KOH}$ (290 mOsm). The external $\mathrm{NaCl}$ Ringer's solution was supplemented with picrotoxin $\left(\begin{array}{lll}50 & \mu \mathrm{M}\end{array}\right)$ and 2,3-dihydroxy-6-nitro-7-sulfonylbenzo[f] quinoxaline $(10 \mu \mathrm{M})$ to block $\mathrm{GABA}_{\mathrm{A}}$ receptor-mediated and non-NMDA receptor-mediated responses, respectively. The flow rate of all perfusing solutions was fairly rapid at $75-125 \mathrm{ml} / \mathrm{h}$.

Data analysis. $I_{\mathrm{K}(\mathrm{M})}$ amplitude was measured as the relaxation current in response to a voltage step protocol from $-20 \mathrm{mV}$ to return potentials of $-50,-60$, and $-70 \mathrm{mV}$. $I_{\mathrm{K}(\mathrm{M})}$ density was calculated as $I_{\mathrm{K}(\mathrm{M})}$ amplitude (in picoamperes)/whole-cell capacitance (in picofarads) for each cell. Kinetic analysis was performed by fitting the deactivation phase of the $I_{\mathrm{K}(\mathrm{M})}$ trace with the standard single-component exponential fit equation as follows: $f(t)=A_{i} \times e^{-t / \tau i}+C$. The $y$-axis was zeroed at the steady state for current deactivation at each hyperpolarizing step, and the fits were extrapolated to zero time.

The effects of LPD and RGB were monitored with respect to holding current in response to the $-20 \mathrm{mV}$ step, as well as $I_{\mathrm{K}(\mathrm{M})}$ amplitude in response to the return step. Half-maximal inhibition $\left(\mathrm{IC}_{50}\right)$ and enhancement $\left(\mathrm{EC}_{50}\right)$ values were calculated using the following Hill equation: $y / y_{\max }=y_{\mathrm{o}}+\left[a x^{b} /\left(c^{b}+x^{b}\right)\right]$. The effects of TEA on $I_{\mathrm{K}(\mathrm{M})}$ amplitude were also examined. Strain-dependent differences in drug effects were determined by two-way ANOVA analysis using Prism 4.0 (GraphPad Software, San Diego, CA).

Passive membrane properties and action potential trains were recorded in current-clamp mode using a series of current steps ranging from -80 to $+180 \mathrm{pA}$. Action potential generation was monitored in slices prepared from B6 and Szt1 mice, in the presence and absence of LPD and RGB. Membrane potential was maintained at $-65 \mathrm{mV}$ by direct current injection (in control and drug conditions) as needed. The ability of CA1 neurons to accommodate action potential frequency was determined by plotting interspike interval number versus normalized spike frequency. Each cell served as its own control, and the frequency of each subsequent interspike interval was normalized to that of the first interspike interval. Significant differences in spike frequency adaptation (SFA) between strains and drug treatments were then determined by nonlinear regression analysis (Prism 4.0). Decreased steepness of the fit is interpreted as decreased SFA. Statistical significance was determined by comparison of the best-fit lines.

\section{Results}

\section{Intrinsic electrophysiological properties of B6 and Szt1 neurons}

Previous characterization of Szt1 mice established that the Szt1 mutation reduces seizure threshold and alters sensitivity to M-channel-modifying drugs (Otto et al., 2004); however, these changes in whole-animal behavior could not necessarily be attributed to the Kcnq2 component of Szt1. Therefore, we recorded $I_{\mathrm{K}(\mathrm{M})}$ in CA1 neurons in brain slices prepared from B6 and Szt1 mice in an effort to characterize changes in $I_{\mathrm{K}(\mathrm{M})}$ specifically. Several fundamental membrane properties were evaluated in CA1 pyramidal neurons in brain slices prepared from B6 and Szt1 mice. The Szt1 mutation does not significantly alter resting membrane potential, holding current (at $-20 \mathrm{mV}$ ), input and series resistance (at $-70 \mathrm{mV}$ ), action potential half-width, action po- 
Table 1. Intrinsic electrophysiological properties of CA1 neurons recorded in brain slices prepared from B6 and Szt1 mice

\begin{tabular}{lcccc}
\hline Membrane property & B6 & $n$ & Szt1 & $n$ \\
\hline Resting membrane potential $(\mathrm{mV})$ & $-60.1 \pm 0.4$ & 19 & $-59.7 \pm 0.4$ & 19 \\
Holding current at $-20 \mathrm{mV}(\mathrm{pA})$ & $261 \pm 22$ & 28 & $280 \pm 31$ & 31 \\
Input resistance $(\mathrm{M} \Omega)$ & $111 \pm 4$ & 38 & $105 \pm 4$ & 40 \\
Series resistance $(\mathrm{M} \Omega)$ & $13.2 \pm 0.5$ & 38 & $13.4 \pm 0.5$ & 40 \\
Spike half-width $(\mathrm{ms})$ & $1.52 \pm 0.04$ & 19 & $1.53 \pm 0.04$ & 18 \\
Spike threshold $(\mathrm{mV})$ & $-46.2 \pm 0.7$ & 19 & $-45.0 \pm 0.7$ & 18 \\
$I_{\text {K(M) }}$ deactivation kinetics $(\tau$ in $\mathrm{ms})$ & $157 \pm 13$ & 17 & $140 \pm 15$ & 17 \\
\hline
\end{tabular}

None of the parameters measured differed between CA1 neurons in slices prepared from B6 and Szt1 mice ( $p>0.5$, ANOVA). Resting membrane potential, input resistance, and series resistance were taken from values reported by SealTest and MultiClamp Commander functions. Spike half-width and spike threshold values were calculated from the first action potential that was generated in response to the lowest depolarizing current injection. $\tau$ values were calculated by fitting the $I_{K(M)}$ deactivation phase with a single-exponential equation.

A

a

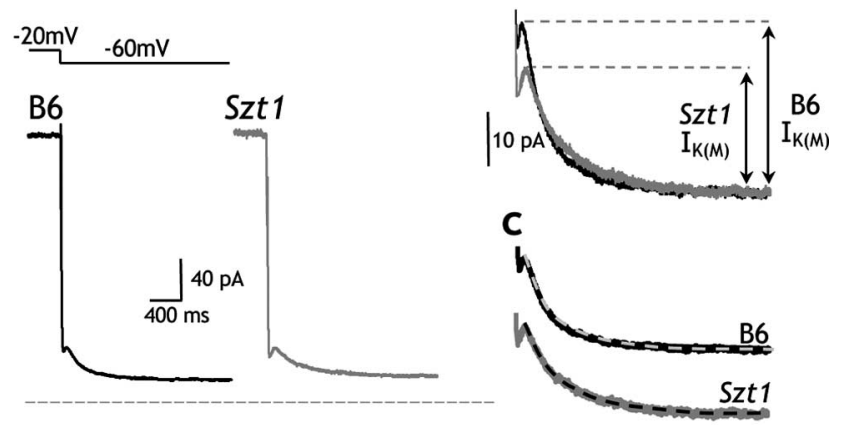

B
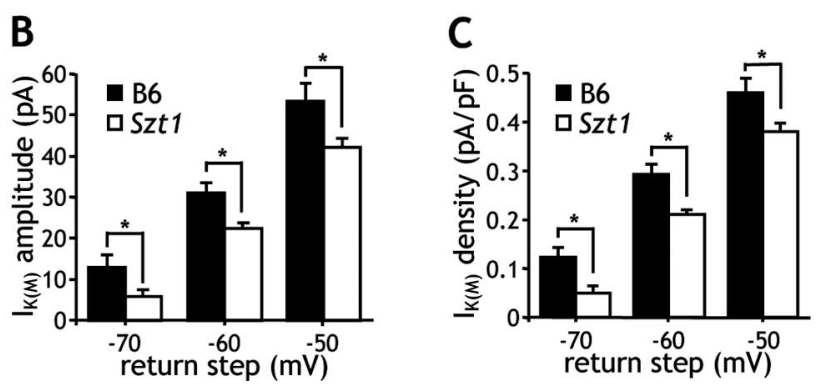

Figure 1. Szt1 reduces $M$-current amplitude and current density in CA1 pyramidal neurons of the hippocampus. Aa, Representative $I_{\text {K(M) }}$ traces recorded from B6 (black trace) and Szt 1 (gray trace) CA1 neurons in response to the -20 to $-60 \mathrm{mV}$ step. The dashed line represents the zero-current level for both traces. $\boldsymbol{A} \boldsymbol{b}$, The same traces enlarged illustrate the decreased M-current amplitude observed in Szt1 slices. Dotted lines show the peak amplitudes of $I_{\mathrm{K}(\mathrm{M})}$ observed in each genotype. Ac, $I_{\mathrm{K}(\mathrm{M})}$ deactivation kinetics are similar in $\mathrm{B} 6$ and Szt7 slices (for $\tau$ values, see Table 1). The same traces are normalized for comparison of deactivation kinetics. First-order exponential fits (dotted lines) are superimposed. $\boldsymbol{B}$, Szt 1 significantly decreases $I_{K(M)}$ amplitude across a range of return voltage steps $\left({ }^{*} p<0.01,-70\right.$ and $-50 \mathrm{mV}$ steps; ${ }^{*} p<$ $0.001,-60 \mathrm{mV}$ step). $C, I_{\mathrm{K}(\mathrm{M})}$ density is reduced in $\mathrm{Szt} 1 \mathrm{CA} 1$ neurons relative to $\mathrm{B} 6$ littermates $\left({ }^{*} p<0.01,-70\right.$ and $-50 \mathrm{mV}$ steps; ${ }^{*} p<0.001,-60 \mathrm{mV}$ step $)$.

tential threshold, $I_{\mathrm{K}(\mathrm{M})}$ deactivation kinetics, or cell capacitance (as mentioned above). These data are summarized in Table 1.

\section{Effects of Szt1 mutation on $I_{\mathrm{K}(\mathrm{M})}$ amplitude and density}

Mice of both genotypes exhibited a functional $I_{\mathrm{K}(\mathrm{M})}$ with a characteristic deactivation tail (Fig. $1 \mathrm{Aa}$ ). In slices prepared from $\mathrm{Szt} 1$ mice, CA1 neurons exhibited decreased $I_{\mathrm{K}(\mathrm{M})}$ amplitudes relative to B6 slices (Fig. $1 A b$ ), a trend that was evident throughout a range of hyperpolarizing steps (from a command potential of -20 to $-50,-60$, and $-70 \mathrm{mV}$ return steps) (Fig. $1 B$ ). Expo- nential fits revealed no significant differences in the kinetics of $I_{\mathrm{K}(\mathrm{M})}$ deactivation between B6 and Szt1 CA1 neurons (Fig. $1 A c)$. Because a decrease in current amplitude could be explained by a decrease in CA1 neuron size, whole-cell capacitance was measured, and $I_{\mathrm{K}(\mathrm{M})}$ amplitude was corrected to $I_{\mathrm{K}(\mathrm{M})}$ density. Whole-cell capacitance measures were similar for CA1 neurons in Szt1 and B6 slices [115.7 \pm 3.9 $\mathrm{pF}(n=40)$ and $111.3 \pm 3.8 \mathrm{pF}(n=38)$, respectively]; therefore, in Szt1 slices, $I_{\mathrm{K}(\mathrm{M})}$ density in CA1 neurons was significantly decreased relative to B6 slices (Fig. 1C). $I_{\mathrm{K}(\mathrm{M})}$ amplitude and density values for B6 and Szt 1 CA1 neurons in response to several return voltage steps are shown in Table 2, and $\tau$ values obtained from deactivation phase exponential fits are listed in Table 1.

Functional consequences of reduced $I_{\mathrm{K}(\mathrm{M})}$ in spike frequency adaptation

$I_{\mathrm{K}(\mathrm{M})}$ activation regulates action potential generation and facilitates SFA; in response to membrane depolarization, $I_{\mathrm{K}(\mathrm{M})}$ repolarizes neurons and decreases input resistance, which attenuates action potential frequency (Goh and Pennefather, 1987; Yue and Yaari, 2004). To test whether the decreased $I_{\mathrm{K}(\mathrm{M})}$ density observed in Szt1 slices causes any observable changes in neuronal excitability, we monitored SFA in CA1 neurons in response to prolonged depolarization steps. In response to a $+120 \mathrm{pA}$ depolarizing current injection of $800 \mathrm{~ms}$ duration, action potential trains were elicited in B6 and Szt1 slices (Fig. 2A). Interspike interval number versus normalized frequency plots were created, and the data were fit with a single-exponential equation. The nonlinear fits were then compared by regression analysis to examine differences in SFA (Prism 4.0; GraphPad Software). Szt1 CA1 neurons $(n=10)$ exhibited significantly less SFA across the course of the response train compared with B6 CA1 neurons ( $n=$ $13)$ (Fig. 2 B). Application of LPD $(10 \mu \mathrm{M})$ to B6 $(n=7)$ and Szt1 $(n=9)$ CA1 neurons significantly inhibits SFA (Fig. 2C,D). It is particularly noteworthy that SFA in B6 CA1 neurons can essentially be converted to that of untreated $S z t 1$ neurons by applying LPD (Fig. 2C). These results suggest that a hypofunctional $I_{\mathrm{K}(\mathrm{M})}$ compromises the ability of neurons to modulate action potential firing and further confirm the significant role of $I_{\mathrm{K}(\mathrm{M})}$ in regulating neuronal excitability.

\section{Pharmacologic effects of LPD in CA1 neurons}

Previous experiments demonstrated that Szt1 mice are hypersensitive to the proconvulsant effects of LPD (Otto et al., 2004). To better describe LPD pharmacology in these mice, we examined the effects of LPD on $I_{\mathrm{K}(\mathrm{M})}$ amplitude and holding current (at a $-20 \mathrm{mV}$ holding potential) in B6 ( $n=5-12$ per dose) and Szt1 ( $n=5-13$ per dose) CA1 neurons. LPD dose dependently blocked $I_{\mathrm{K}(\mathrm{M})}$ and reduced holding current amplitudes (Fig. $3 \mathrm{~A}$ ) but more potently inhibited $I_{\mathrm{K}(\mathrm{M})}$ amplitude in Szt1 slices (Szt1, $\mathrm{IC}_{50}, 1.7 \pm 0.6 \mu \mathrm{M} ; \mathrm{B} 6, \mathrm{IC}_{50}, 4.0 \pm 0.8 \mu \mathrm{M}$ ) (Fig. $3 B$ ). This Szt1induced shift in LPD $\mathrm{IC}_{50}$ was small but statistically significant $(p=0.045)$. Holding currents in B6 and Szt1 CA1 neurons appear to be equally sensitive to LPD in this paradigm (Fig. 3C). These data suggest that the Szt1 mutation results in increased LPD potency in some, but not all, aspects of $I_{\mathrm{K}(\mathrm{M})}$ function. 


\section{Pharmacologic effects of RGB in CA1 neurons}

Szt1 mice exhibit a decreased sensitivity to the anticonvulsant effects of RGB (Otto et al., 2004). We therefore examined the effects of RGB on $I_{\mathrm{K}(\mathrm{M})}$ amplitude and holding current in CA1 neurons of B6 $(n=$ 5-10 per dose) and Szt1 $(n=5-12$ per dose) CA1 neurons. The effects of RGB on slices prepared from each group were quite disparate. Sample traces illustrate differences in the responsiveness of B6 and Szt1 neurons to RGB after hyperpolarizing steps to $-60 \mathrm{mV}$ from a holding potential of $-20 \mathrm{mV}(10 \mu \mathrm{M})$ (Fig. $4 \mathrm{~A}$, gray traces). Whereas B6 slices exhibited dosedependent enhancement of $I_{\mathrm{K}(\mathrm{M})}$ amplitude in the presence of RGB, remarkably, in Szt1 slices, RGB was not able to significantly enhance $I_{\mathrm{K}(\mathrm{M})}$ amplitude at any concentration tested (Fig. $4 B$ ). Given this fact, it is particularly surprising that RGB $(10 \mu \mathrm{M})$ still retained its ability to prolong $I_{\mathrm{K}(\mathrm{M})}$ deactivation kinetics in Szt1 slices, just as it did in B6 slices (Fig. 4A, insets, $C)$. Consistent with a previous study (Passmore et al., 2003), RGB does not allow complete current inactivation at high concentrations, which precludes accurate measurement of $I_{\mathrm{K}(\mathrm{M})}$ amplitude; thus, it was not possible to construct full RGB dose-response curves.

Szt1 CA1 neurons exhibited a 10 -fold decrease in RGB potency with respect to holding current enhancement when measured at $-20 \mathrm{mV}\left(\mathrm{B} 6, \mathrm{ED}_{50}, 3.5 \pm 0.4 \mu \mathrm{M}\right.$; Szt1, $\mathrm{ED}_{50}, 31.2 \pm 0.4 \mu \mathrm{M}$ ) (Fig. $4 D$ ). However, $10 \mu \mathrm{M}$ RGB induced a hyperpolarization from resting membrane potential of B6 and Szt1 neurons to a similar degree (by $6.8 \pm 2.9$ and $7.1 \pm 3.4 \mathrm{mV}$, respectively), suggesting that, at more hyperpolarized potentials, RGB may enhance the amplitude of the M-current. The $I_{\mathrm{K}(\mathrm{M})}$ pharmacology data as a whole show that LPD and RGB can affect some aspects of $I_{\mathrm{K}(\mathrm{M})}$ physiology but not others; thus, these results suggest the existence of multiple populations of M-channels with differing KCNQ stoichiometric arrangements.

\section{Effects of TEA on $I_{\mathrm{K}(\mathrm{M})}$ in CA1 neurons}

The differential LPD and RGB pharmacodynamics observed in B6 and Szt1 CA1 neurons suggested that Szt1 results in altered M-channel subunit composition. To further test this hypothesis, we examined the effects of TEA (10 mM), a KCNQ2 subunitpreferring $I_{\mathrm{K}(\mathrm{M})}$ blocker (Hadley et al., 2000), on $I_{\mathrm{K}(\mathrm{M})}$ amplitude in B6 and Szt1 CA1 neurons. TEA significantly blocked $I_{\mathrm{K}(\mathrm{M})}$ in B6 CA1 neurons $(n=5)$ (Fig. 5). In contrast, the $I_{\mathrm{K}(\mathrm{M})}$ recorded from Szt1 CA1 neurons $(n=5)$ was insensitive to TEA. Two-way ANOVA analysis revealed that Szt1 CA1 neurons displayed significantly decreased TEA sensitivity relative to B6 CA1 neurons same genotype.
Table 2. $I_{\mathrm{K}(\mathrm{M})}$ amplitude and density values are reduced across a range of voltage steps in Szt1 CA1 neurons

\begin{tabular}{llllll}
\hline & \multicolumn{2}{l}{$I_{\mathrm{K}(\mathrm{M})}$ amplitude $(\mathrm{pA})$} & & \multicolumn{2}{l}{$I_{\mathrm{K}(\mathrm{M})}$ density $(\mathrm{pA} / \mathrm{pF})$} \\
\cline { 2 - 3 } \cline { 6 - 7 } Step from $-20 \mathrm{mV}$ & $\mathrm{B} 6$ & & \multicolumn{1}{l}{ Szt1 } & Szt1 \\
\hline$-50 \mathrm{mV}$ & $53.3 \pm 4.6(12)$ & $42.3 \pm 2.0^{*}(13)$ & & $0.46 \pm 0.03$ & $0.38 \pm 0.02^{*}$ \\
$-60 \mathrm{mV}$ & $33.9 \pm 2.4(34)$ & $23.2 \pm 1.2^{*}(28)$ & & $0.29 \pm 0.02$ & $0.21 \pm 0.01^{*}$ \\
$-70 \mathrm{mV}$ & $13.0 \pm 3.0(12)$ & $5.8 \pm 1.7^{*}(12)$ & & $0.12 \pm 0.02$ & $0.05 \pm 0.02^{*}$ \\
\hline
\end{tabular}

$I_{\mathrm{K}(\mathrm{M})}$ amplitude values were measured at various potentials in response to hyperpolarizing steps from -20 to $-50,-60$, and $-70 \mathrm{mV}$. In response to al three hyperpolarizing return steps, Szt 1 CA1 neurons exhibited significantly decreased $I_{K(M)}$ amplitude relative to that of $B 6$ mice. Szt 1 CA1 neurons also show a significantly decreased $I_{\mathrm{K}(\mathrm{M})}$ density at the same hyperpolarizing return steps $\left({ }^{*} p<0.05\right.$, ANOVA). Current densities were calculated by dividing the $I_{\mathrm{K}(\mathrm{M})}$ amplitude of each cell by its capacitance. The numbers of cells recorded from (in parentheses) are identical for $I_{\mathrm{K}(\mathrm{M})}$ amplitude and density values within the
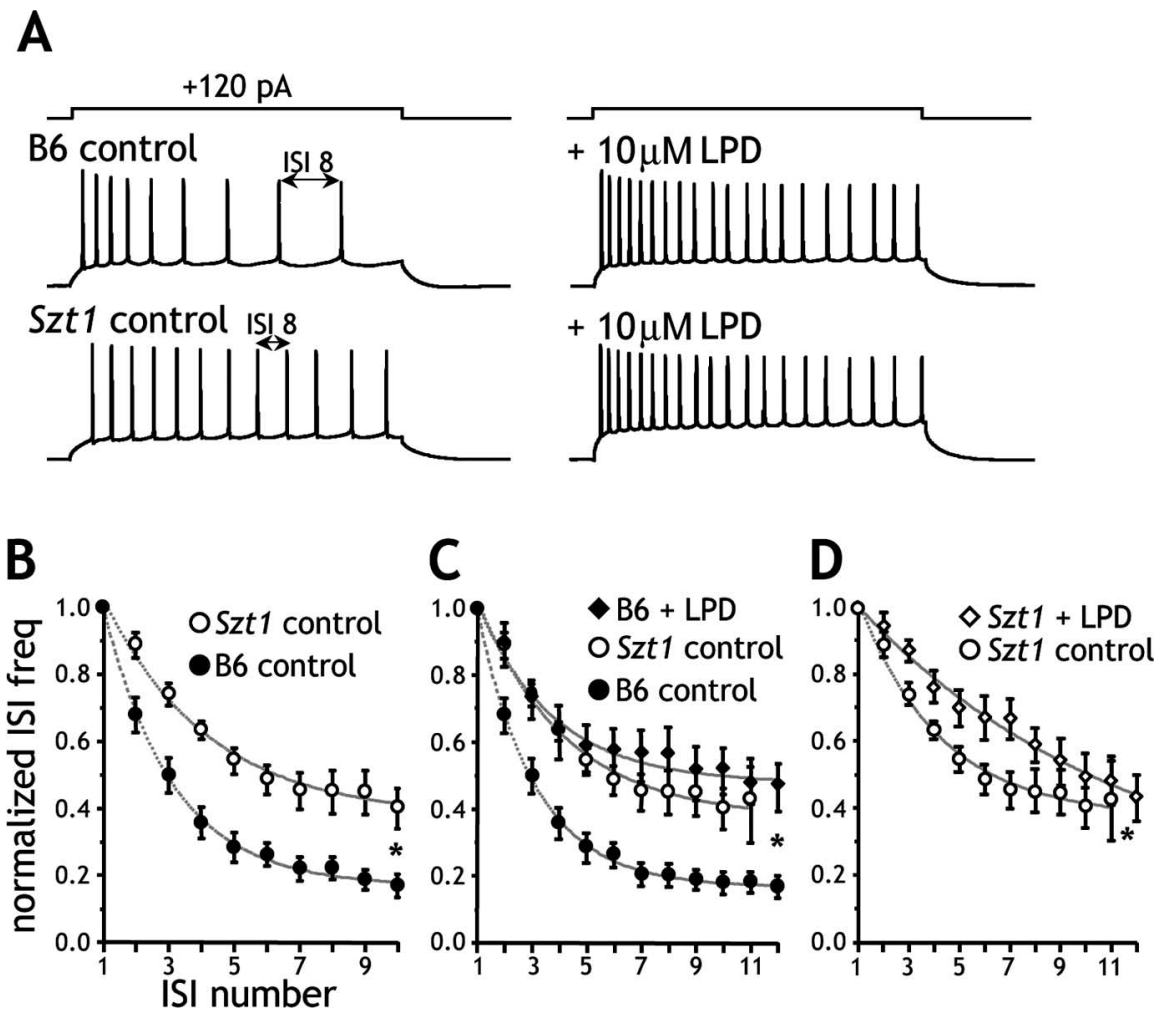

Figure 2. Szt1 reduces the ability of CA1 neurons to adapt spike frequency. A, Sample traces from CA1 neurons in B6 and Szt 1 slices illustrate SFA from the beginning to the end of the +120 pA, 800-ms-long, depolarizing current injection. In the B6 control trace, spike frequency decreases over time such that the interspike frequency is decreased relative to the first interspike frequency. Notice in the Szt1 control trace that spike frequency is relatively uniform from the beginning to the end of the trace. Interspike interval (ISI) 8 is shown in both traces to illustrate differences in response to prolonged depolarization. Application of LPD (10 $\mu \mathrm{M})$ decreases SFA in both B6 and Szt 1 slices. B, Spike frequency throughout the depolarizing step was normalized to the frequency (the reciprocal) of the first interspike interval. Szt1 slices exhibit significantly less SFA than B6 slices, as indicated by the decreased steepness of the best-fit line $\left({ }^{*} p<0.0005\right.$, nonlinear regression analysis). $C$, In the presence of LPD, B6 SFA is significantly reduced $\left(^{*} p<0.0001\right.$, nonlinear regression analysis) to a level resembling that of untreated Szt1 slices (B6 + LPD vs Szt1 control, not significant). D, LPD also significantly decreases SFA in Szt1 slices ( ${ }^{*} p<0.01$, nonlinear regression analysis).

(Fig. 5B). These data support our hypothesis that M-channel subunit composition differs in Szt1 and B6 CA1 neurons.

\section{Discussion}

Compounds that block $I_{\mathrm{K}(\mathrm{M})}$ are proconvulsant (Flagmeyer et al., 1995), whereas those that enhance $I_{\mathrm{K}(\mathrm{M})}$ are anticonvulsant (Rostock et al., 1996), and, in oocytes, several mutations in Kcnq2 and Kcnq3 genes have been shown to decrease KCNQ2/KCNQ3 channel function. It has been assumed that KCNQ mutations decrease native (neuronal) $I_{\mathrm{K}(\mathrm{M})}$ function, thereby increasing neuronal excitability and eventually causing the seizures observed in BFNC patients (Castaldo et al., 2002). However, until now, it has not been determined whether such mutations actually affect the native neuronal $I_{\mathrm{K}(\mathrm{M})}$. We have shed significant light on 
A

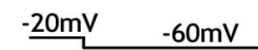

\section{B6}
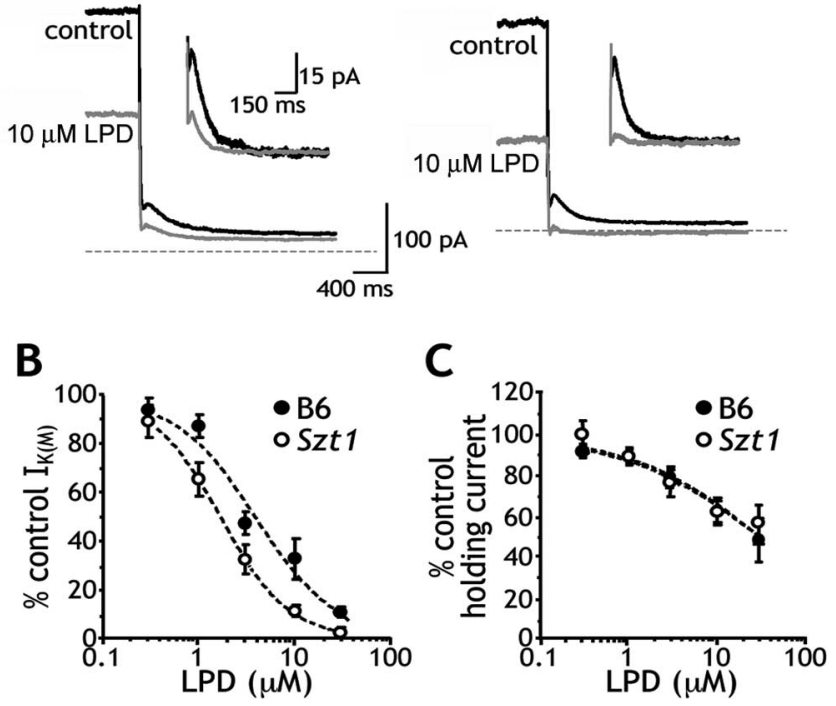

Figure 3. Szt 1 confers increased sensitivity to the $I_{\mathrm{K}(\mathrm{M})}$ blocking properties of LPD. A, Sample traces show the inhibitory effects of $L P D$ on the holding current at a $-20 \mathrm{mV}$ holding potential and $I_{\mathrm{K}(\mathrm{M})}$ amplitude. Traces in control (black) and $10 \mu \mathrm{M}$ LPD (gray) conditions illustrate that Szt 1 slices exhibit increased sensitivity to the $I_{K(M)}$ blocking effects of LPD. Inset, Sample traces have zeroed baselines and magnified $y$-axes to more clearly illustrate these effects. $B$, LPD dose-response curves show that Szt1 CA1 neurons exhibit increased sensitivity to LPD with respect to $I_{\mathrm{K}(\mathrm{M})}$ amplitude $\left(S z t 7, I_{50}, 1.7 \pm 0.6 \mu \mathrm{m} ; \mathrm{B} 6, \mathrm{IC}_{50}, 4.0 \pm 0.8 \mu \mathrm{m}\right)$. A statistical comparison identifies the shift in $\mathrm{IC}_{50}$ as significant $\left({ }^{*} p<0.05\right)$. $\mathrm{C}, \mathrm{B} 6$ and Szt 1 CA1 neurons appear equally sensitive to the LPD-induced decrease in holding current at the $-20 \mathrm{mV}$ holding potential.

the consequences of a naturally occurring KCNQ2 mutation using mice heterozygous for the Szt1 mutation, which deletes the genomic DNA encoding the KCNQ2 C terminus, and all of CHRNA4 and ARFGAP-1. The Szt1 mutation is of particular significance to BFNC because a Czech family with this seizure disorder has been found to possess a genomic deletion of the KCNQ2 C terminus (Pereira et al., 2004).

It was shown recently that conditional transgenic overexpression of a dominant-negative Kcnq2 G279S mutation reduces $I_{\mathrm{K}(\mathrm{M})}$ amplitude and increases neuronal excitability in mice (Peters et al., 2005). The Tet-Off system used to drive conditional Kcnq2 overexpression in this study, however, significantly interfered with the expression of wild-type KCNQ2 and KCNQ3 subunits. Because of the pervasive alterations in M-channel subunit expression levels, these results might be considered to be detached from any real disease pathology.

The results presented here are the first direct evidence of decreased native neuronal $I_{\mathrm{K}(\mathrm{M})}$ amplitude and current density in a naturally occurring animal model of Kcnq2 mutation. The decrease in current amplitude and density may be attributable to a depolarizing shift in the $I_{\mathrm{K}(\mathrm{M})}$ voltage of activation or decreased peak channel conductance, a distinction that cannot be made in the acute brain slice recording paradigm. There were, however, no observed changes in deactivation kinetics as a function of voltage; thus, the data imply that Szt1 does not alter the voltage dependence of $I_{\mathrm{K}(\mathrm{M})}$ activation. We have also shown that $I_{\mathrm{K}(\mathrm{M})}$ hypofunctionality increases the excitability of CA1 neurons by compromising their natural ability to accommodate action potential frequency. Finally, the reduction in $I_{\mathrm{K}(\mathrm{M})}$ amplitude and SFA and altered pharmacology in Szt1 CA1 neurons are consis-
A
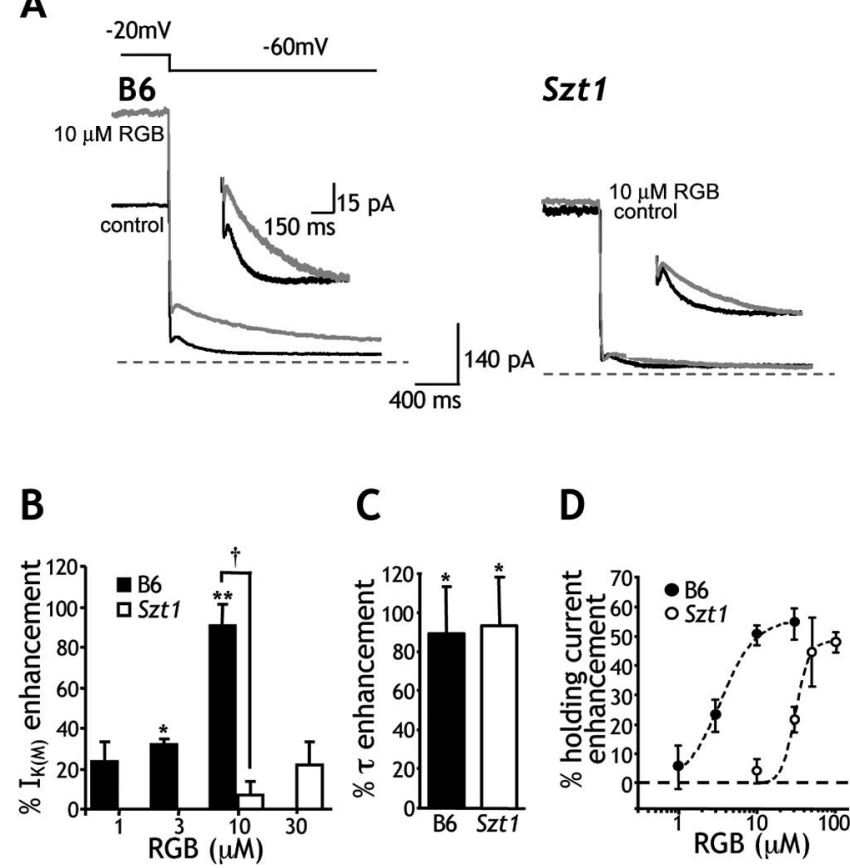

C

D

Figure 4. Szt1 confers decreased sensitivity to the $I_{\mathrm{K}(\mathrm{M})}$ enhancing properties of RGB. A, Sample traces in control (black) and $10 \mu \mathrm{M}$ RGB (gray) illustrate that Szt 1 CA1 neurons exhibit decreased sensitivity to the $I_{K(M)}$ enhancing effects of RGB. B, Szt1 slices exhibit dramatically decreased sensitivity to the $I_{K(M)}$ amplitude enhancing effects of RGB. Although 3 and $10 \mu \mathrm{M}$ RGB significantly enhance $I_{K(M)}$ amplitude in $B 6$ slices, $I_{K(M)}$ amplitude is not enhanced by $R G B$ at any concentration in Szt1 slices. The effects of $10 \mu \mathrm{M}$ RGB differ significantly between B6 and Szt1 slices ( ${ }^{\dagger} p<0.0005$, two-way ANOVA, drug effect vs mouse genotype comparison). ${ }^{*} p<0.05$; ${ }^{* *} p<0.02$. Notice, however, that RGB does prolong $I_{\mathrm{K}(\mathrm{M})}$ deactivation kinetics in Szt1 slices (A, inset, $C$ ). C, RGB significantly and similarly prolongs the $I_{\mathrm{K}(\mathrm{M})} \tau$ of deactivation in CA1 neurons of $B 6$ and $S z t 1$ mice. ${ }^{*} p<0.02$. D, Dose-response curves show that $S z t 1$ slices are $\sim 10$-fold less sensitive to the effects of RGB on holding current at $-20 \mathrm{mV}$ (Szt1, $\mathrm{EC}_{50}, 31.2 \pm$ $\left.0.4 \mu \mathrm{m} ; \mathrm{B} 6, \mathrm{EC}_{50}, 3.5 \pm 0.4 \mu \mathrm{M}\right)$. The RGB EC 50 shift in Szt 1 CA1 neurons was significant at $p<$ 0.05. Interestingly, the Hill coefficient was also increased in Szt1 slices (B6, $n^{H}=2.0 ;$ Szt1, $\left.n^{\mathrm{H}}=5.0\right)$.

tent with the decreased seizure threshold and altered pharmacosensitivity, respectively, that were reported previously in the Szt1 mouse behavioral study (Otto et al., 2004).

Kcnq 2 mRNA is reduced in Szt1/+ mice by $30-40 \%$ and is seemingly absent in Szt1 $+/+$ mice (Yang et al., 2003), suggesting that the truncated form of the protein is not likely expressed. Furthermore, the KCNQ2 C terminus is required for proper KCNQ2/KCNQ3 channel assembly (Schwake et al., 2003). In CA1 pyramidal neurons, KCNQ2 protein is normally concentrated at the nodes of Ranvier and the axon initial segment (AIS), the anatomical site of action potential initiation (Devaux et al., 2004). Therefore, one possible explanation for alterations in SFA and $I_{\mathrm{K}(\mathrm{M})}$ density in the Szt1 mouse is that KCNQ2 protein expression is decreased at the AIS. Although it is possible that a trace amount of truncated Kcnq2 mRNA is being generated for the Szt1 allele, causing a dominant-negative affect, the phenotypic similarities between mice homozygous for Szt1 and Kcnq2 null mice (Watanabe et al., 2000; Yang et al., 2003) and the inability to detect mRNA encoding the truncated protein suggest a KCNQ2 haploinsufficiency, consistent with the proposed human disease mechanism (Steinlein, 2004).

It is especially interesting that the SFA of B6 neurons can essentially be converted to that of untreated Szt1 slices by partially blocking $I_{\mathrm{K}(\mathrm{M})}$ with $10 \mu \mathrm{M} \mathrm{LPD}$. This result is consistent with the hypothesis that proper $I_{\mathrm{K}(\mathrm{M})}$ function is an important component 
of normal SFA (Goh and Pennefather, 1987; Aiken et al., 1995). Another group, however, has shown that LPD does not affect SFA in cultured mouse and rat superior cervical ganglion neurons (Romero et al., 2004), although neurons of this population are not implicated in epilepsy. This discrepancy in LPD effect could be explained by the clear differences in the baseline SFA of cultured SCG neurons versus hippocampal CA1 neurons in the acute brain slice preparation.

We also detailed several differences in Szt1 CA1 neuron $I_{\mathrm{K}(\mathrm{M})}$ pharmacology. These results are noteworthy in that they imply that $\mathrm{M}$-channels with differing KCNQ subunit combinations exist in CA1 pyramidal neurons as a downstream effect of the Szt1 mutation. A dramatic and interesting pharmacological change observed was the substantially decreased RGB potency with respect to both $I_{\mathrm{K}(\mathrm{M})}$ amplitude and holding current at $-20 \mathrm{mV}$. Although RGB did not enhance $I_{\mathrm{K}(\mathrm{M})}$ amplitude at any concentration (0.3-100 $\mu \mathrm{M}$; data not shown), it did substantially prolong $I_{\mathrm{K}(\mathrm{M})}$ deactivation kinetics in both B6 and Szt1 CA1 neurons at all voltage steps tested. In addition, at the CA1 neuron resting membrane potential $(-70 \mathrm{mV})$, at which $I_{\mathrm{K}(\mathrm{M})}$ is weakly but tonically active, Szt1 neurons were still hyperpolarized in the presence of RGB and to a similar degree as that which was observed in B6 neurons. These persistent actions of RGB suggest an upregulation of the KCNQ3 subunit as a consequence of the Szt1 mutation. The open probability of channels containing KCNQ3 subunits is substantially greater than channels containing KCNQ2 subunits (Selyanko et al., 2001; Li et al., 2004). Therefore, at a holding potential of $-20 \mathrm{mV}$, near-maximal activation of M-channels might be achieved in the Szt1 neurons. It would then not be surprising that RGB would not enhance M-current amplitude in these cells but could still prolong deactivation and hyperpolarize cells from rest.

The most substantial evidence for altered KCNQ subunit stoichiometry in Szt1 CA1 neurons is the sizeable difference in sensitivity to the KCNQ2-preferring $I_{\mathrm{K}(\mathrm{M})}$ blocker TEA (Hadley et al., 2000). B6 CA1 neurons showed significant block of both holding current and M-current amplitude, indicating the presence of KCNQ2 subunits. Szt1 CA1 neurons, however, were essentially insensitive to TEA. These data strongly suggest that the Szt1 mutation reduces KCNQ2 subunit inclusion in the $\mathrm{M}$-channel. It is possible that either the KCNQ3 and/or KCNQ5 subunits are upregulated in Szt1 mice to compensate for a partial loss of KCNQ2. This would be consistent with the known insensitivity to TEA for both KCNQ3 and KCNQ5 (Hadley et al., 2000) and also the lack of change in resting membrane potential and holding currents in Szt1 CA1 neurons.

Finally, it is worth noting that the increased LPD potency observed in Szt1 neurons, although statistically significant, is quantitatively small. The $\mathrm{IC}_{50}$ is only shifted from $4.0 \pm 0.8 \mu \mathrm{M}$ in B6 neurons to $1.7 \pm 0.6 \mu \mathrm{M}$ in Szt1 neurons. Indeed, this slight change may not be functionally meaningful. Nevertheless, in a previous electroconvulsive seizure threshold study, Szt1 mice displayed a similar small but statistically significant increase in LPD potency (Otto et al., 2004). In that study, $\mathrm{LPD} \mathrm{ED}_{50}$ values were determined at $7.6 \pm 1.0$ and $3.4 \pm 1.1 \mathrm{mg} / \mathrm{kg}$ in B6 and $S z t 1$ mice, respectively.
B

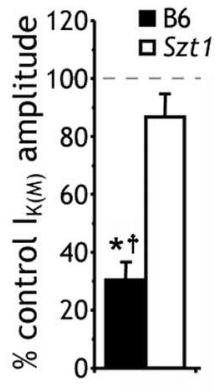

\section{$400 \mathrm{~ms}$}

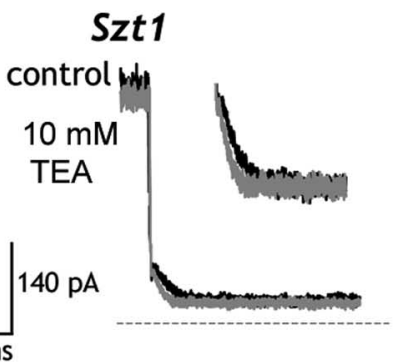

blocker TEA. $A$, Sample traces in control (black) and $10 \mathrm{~mm}$ TEA (gray) illustrate that $S z t 1$ CA1 neurons exhibit decreased sensitivity to the $I_{K(M)}$. blocking effects of TEA. $B$, Szt1 slices display significantly decreased sensitivity to the $I_{\mathrm{K}(\mathrm{M})}$ blocking effects of TEA. TEA at $10 \mathrm{~mm}$ significantly blocks (iv) B6 CA1 neurons ( ${ }^{*} p<0.01$, paired $t$ test). Szt 1 slices display less sensitivity to TEA than B6 slices ( ${ }^{\dagger} p<0.02$, two-way ANOVA, drug effect vs genotype comparison).

It has been established that $I_{\mathrm{K}(\mathrm{M})}$ is a major contributor to the resting membrane potential of many neurons. Pharmacological block or enhancement of $I_{\mathrm{K}(\mathrm{M})}$ depolarizes or hyperpolarizes resting membrane potential, respectively (Aiken et al., 1995; Otto et al., 2002; Peretz et al., 2005). Surprisingly, however, we found no significant change in resting membrane potential between B6 and Szt1 mice. This finding also supports the hypothesis that compensatory mechanisms may have arisen in the Szt1 mice to prevent a significant change in resting membrane potential. Altered expression of numerous voltage-gated ion channels and other related proteins in Szt1 mice (e.g., potassium leak currents or an increase in the $\mathrm{Na}^{+}-\mathrm{K}^{+}$ATPase) might account for the lack of a change in either holding current or resting membrane potential. However, this interpretation is complicated by the lack of differential effect observed on holding current in the presence of LPD, unlike RGB and TEA application. However, regardless of the myriad potential molecular mechanisms underlying the pharmacodynamic discrepancies presented here, it is particularly compelling that the M-channel pharmacology is so consistent with previous in vivo electroconvulsive threshold studies (Otto et al., 2004), in which Szt1 mice displayed decreased LPD sensitivity and quite robustly decreased RGB sensitivity.

The Szt1 mutation does alter another epilepsy-related gene, Chrna4, which is implicated in autosomal dominant frontal lobe epilepsy (ADNFLE) (Steinlein et al., 1995; Hirose et al., 1999). Chrna4 hemizygosity may appear to contribute to, or even be fully responsible for, the reduction of seizure threshold observed in the Szt1 mouse, but it might just as well temper the effects of Kcnq2 hemizygosity, because many of the human ADNFLEcausing point mutations in CHRNA4 observed to date are actually gain-of-function, producing receptors with increased ACh sensitivity (Bertrand et al., 2002; Scheffer and Berkovic, 2003). Indeed, it has not been determined yet whether nicotinic ACh receptor hypofunction or hyperfunction underlies ADNFLE. More specific to the Szt1 mutation, Chrna4/+ mice have no known seizure phenotype, and EEGs are similar to wild-type mice (McColl et al., 2003), and extensive seizure threshold testing has revealed only modest differences, with mildly increased sensitivity in some chemoconvulsive models and even resistance in others (Ross et al., 2000; Wong et al., 2002). On these grounds, we suggest that decreased $I_{\mathrm{K}(\mathrm{M})}$ amplitude and subsequently inhibited SFA are the primary source of the lowered seizure threshold observed in the Szt1 mouse and may underlie seizure generation 
in human BFNC patients with C-terminal deletion mutations in KCNQ2. Finally, although KCNQ2 and KCNQ3 mutations are associated with human epilepsy, it is easy to imagine that a current so crucial to regulating neuronal excitability could be a useful pharmacological target for the treatment of many pathologies involving aberrant neuronal excitability.

\section{References}

Aiken SP, Lampe BJ, Murphy PA, Brown BS (1995) Reduction of spike frequency adaptation and blockade of $\mathrm{M}$-current in rat CAl pyramidal neurones by linopirdine (DuP 996), a neurotransmitter release enhancer. Br J Pharmacol 115:1163-1168.

Barton ME, White HS, Wilcox KS (2004) The effect of CGX-1007 and CI1041, novel NMDA receptor antagonists, on NMDA receptor-mediated EPSCs. Epilepsy Res 59:13-24.

Bertrand D, Picard F, Le Hellard S, Weiland S, Favre I, Phillips H, Bertrand S, Berkovic SF, Malafosse A, Mulley J (2002) How mutations in the nAChRs can cause ADNFLE epilepsy. Epilepsia 43 [Suppl 5]:112-122.

Biervert C, Schroeder BC, Kubisch C, Berkovic SF, Propping P, Jentsch TJ, Steinlein OK (1998) A potassium channel mutation in neonatal human epilepsy. Science 279:403-406.

Brown DA, Adams PR (1980) Muscarinic suppression of a novel voltagesensitive $\mathrm{K}^{+}$current in a vertebrate neurone. Nature 283:673-676.

Castaldo P, del Giudice EM, Coppola G, Pascotto A, Annunziato L, Taglialatela M (2002) Benign familial neonatal convulsions caused by altered gating of KCNQ2/KCNQ3 potassium channels. J Neurosci 22:1-6.

Constanti A, Brown DA (1981) M-Currents in voltage-clamped mammalian sympathetic neurones. Neurosci Lett 24:289-294.

Devaux JJ, Kleopa KA, Cooper EC, Scherer SS (2004) KCNQ2 is a nodal $\mathrm{K}^{+}$ channel. J Neurosci 24:1236-1244.

Dost R, Rundfeldt C (2000) The anticonvulsant retigabine potently suppresses epileptiform discharges in the low $\mathrm{Ca}^{2+}$ and low $\mathrm{Mg}^{2+}$ model in the hippocampal slice preparation. Epilepsy Res 38:53-66.

Flagmeyer I, Gebert I, van der Staay FJ (1995) General pharmacology of the putative cognition enhancer linopirdine. Arzneimittelforschung 45:456-459.

Goh JW, Pennefather PS (1987) Pharmacological and physiological properties of the after-hyperpolarization current of bullfrog ganglion neurones. J Physiol (Lond) 394:315-330.

Hadley JK, Noda M, Selyanko AA, Wood IC, Abogadie FC, Brown DA (2000) Differential tetraethylammonium sensitivity of KCNQ1-4 potassium channels. Br J Pharmacol 129:413-415.

Hirose S, Iwata H, Akiyoshi H, Kobayashi K, Ito M, Wada K, Kaneko S, Mitsudome A (1999) A novel mutation of CHRNA4 responsible for autosomal dominant nocturnal frontal lobe epilepsy. Neurology 53:1749-1753.

Li Y, Gamper N, Shapiro MS (2004) Single-channel analysis of KCNQ K ${ }^{+}$ channels reveals the mechanism of augmentation by a cysteine-modifying reagent. J Neurosci 24:5079-5090.

Marrion NV (1997) Control of M-current. Annu Rev Physiol 59:483-504.

McColl CD, Horne MK, Finkelstein DI, Wong JY, Berkovic SF, Drago J (2003) Electroencephalographic characterisation of pentylenetetrazoleinduced seizures in mice lacking the alpha 4 subunit of the neuronal nicotinic receptor. Neuropharmacology 44:234-243.

Otto JF, Kimball MM, Wilcox KS (2002) Effects of the anticonvulsant retigabine on cultured cortical neurons: changes in electroresponsive properties and synaptic transmission. Mol Pharmacol 61:921-927.

Otto JF, Yang Y, Frankel WN, Wilcox KS, White HS (2004) Mice carrying the szt1 mutation exhibit increased seizure susceptibility and altered sensitivity to compounds acting at the m-channel. Epilepsia 45:1009-1016.

Passmore GM, Selyanko AA, Mistry M, Al-Qatari M, Marsh SJ, Matthews EA, Dickenson AH, Brown TA, Burbidge SA, Main M, Brown DA (2003)
$\mathrm{KCNQ} / \mathrm{M}$ currents in sensory neurons: significance for pain therapy. J Neurosci 23:7227-7236.

Pereira S, Roll P, Krizova J, Genton P, Brazdil M, Kuba R, Cau P, Rektor I, Szepetowski P (2004) Complete loss of the cytoplasmic carboxyl terminus of the KCNQ2 potassium channel: a novel mutation in a large Czech pedigree with benign neonatal convulsions or other epileptic phenotypes. Epilepsia 45:384-390.

Peretz A, Degani N, Nachman R, Uziyel Y, Gibor G, Shabat D, Attali B (2005) Meclofenamic acid and diclofenac, novel templates of KCNQ2/Q3 potassium channel openers, depress cortical neuron activity and exhibit anticonvulsant properties. Mol Pharmacol 67:1053-1066.

Peters HC, Hu H, Pongs O, Storm JF, Isbrandt D (2005) Conditional transgenic suppression of $\mathrm{M}$ channels in mouse brain reveals functions in neuronal excitability, resonance and behavior. Nat Neurosci 8:51-60.

Romero M, Reboreda A, Sanchez E, Lamas JA (2004) Newly developed blockers of the M-current do not reduce spike frequency adaptation in cultured mouse sympathetic neurons. Eur J Neurosci 19:2693-2702.

Ross SA, Wong JY, Clifford JJ, Kinsella A, Massalas JS, Horne MK, Scheffer IE, Kola I, Waddington JL, Berkovic SF, Drago J (2000) Phenotypic characterization of an $\alpha 4$ neuronal nicotinic acetylcholine receptor subunit knock-out mouse. J Neurosci 20:6431-6441.

Rostock A, Tober C, Rundfeldt C, Bartsch R, Engel J, Polymeropoulos EE, Kutscher B, Loscher W, Honack D, White HS, Wolf HH (1996) D-23129: a new anticonvulsant with a broad spectrum activity in animal models of epileptic seizures. Epilepsy Res 23:211-223.

Scheffer IE, Berkovic SF (2003) The genetics of human epilepsy. Trends Pharmacol Sci 24:428-433.

Schroeder BC, Kubisch C, Stein V, Jentsch TJ (1998) Moderate loss of function of cyclic-AMP-modulated KCNQ2/KCNQ3 $\mathrm{K}^{+}$channels causes epilepsy. Nature 396:687-690.

Schwake M, Jentsch TJ, Friedrich T (2003) A carboxy-terminal domain determines the subunit specificity of $\mathrm{KCNQ} \mathrm{K}^{+}$channel assembly. EMBO Rep 4:76-81.

Selyanko AA, Hadley JK, Brown DA (2001) Properties of single M-type KCNQ2/KCNQ3 potassium channels expressed in mammalian cells. J Physiol (Lond) 534:15-24.

Shah MM, Mistry M, Marsh SJ, Brown DA, Delmas P (2002) Molecular correlates of the M-current in cultured rat hippocampal neurons. J Physiol (Lond) 544:29-37.

Singh NA, Charlier C, Stauffer D, DuPont BR, Leach RJ, Melis R, Ronen GM, Bjerre I, Quattlebaum T, Murphy JV, McHarg ML, Gagnon D, Rosales TO, Peiffer A, Anderson VE, Leppert M (1998) A novel potassium channel gene, KCNQ2, is mutated in an inherited epilepsy of newborns. Nat Genet 18:25-29.

Steinlein OK (2004) Genetic mechanisms that underlie epilepsy. Nat Rev Neurosci 5:400-408.

Steinlein OK, Mulley JC, Propping P, Wallace RH, Phillips HA, Sutherland GR, Scheffer IE, Berkovic SF (1995) A missense mutation in the neuronal nicotinic acetylcholine receptor alpha 4 subunit is associated with autosomal dominant nocturnal frontal lobe epilepsy. Nat Genet 11:201-203.

Watanabe H, Nagata E, Kosakai A, Nakamura M, Yokoyama M, Tanaka K, Sasai H (2000) Disruption of the epilepsy KCNQ2 gene results in neural hyperexcitability. J Neurochem 75:28-33.

Wong JY, Ross SA, McColl C, Massalas JS, Powney E, Finkelstein DI, Clark M, Horne MK, Berkovic SF, Drago J (2002) Proconvulsant-induced seizures in alpha(4) nicotinic acetylcholine receptor subunit knockout mice. Neuropharmacology 43:55-64.

Yang Y, Beyer BJ, Otto JF, O'Brien TP, Letts VA, White HS, Frankel WN (2003) Spontaneous deletion of epilepsy gene orthologs in a mutant mouse with a low electroconvulsive threshold. Hum Mol Genet 12:975-984.

Yue C, Yaari Y (2004) KCNQ/M channels control spike afterdepolarization and burst generation in hippocampal neurons. J Neurosci 24:4614-4624. 